\title{
Comparison of Bulk and Precipitation Polymerization Method of Synthesis Molecular Imprinted Solid Phase Extraction for Atenolol using Methacrylic Acid
}

\author{
Rimadani Pratiwi, Sandra Megantara, Driyanti Rahayu, Indraswari Pitaloka, Aliya Nur Hasanah* \\ Department of Pharmaceutical Analysis and Medicinal Chemistry, Faculty of Pharmacy, Universitas Padjadjaran, Jatinangor 45363, INDONESIA.
}

\begin{abstract}
Objective: Atenolol is one of beta-blocker are prohibited as doping based on World Anti-Doping Agency (WADA). The purpose of this study was to the synthesis of molecular imprinted polymer (MIP) for extraction of atenolol from the sample. Method: This research compared the two of the method, bulk and precipitation polymerization. The MIP was successfully prepared from methacrylic acid as a functional monomer, ethyleneglycoldimethacrylate as a crosslinker, benzoyl peroxide as an initiator, butanol as a porogenic solvent with atenolol as a template molecule. Result: The result showed that the bulk polymerization method produces sorbents that have good adsorption capacity and small particle compare to the precipitation polymerization. Both methods were selective for atenolol. Conclusion: Generally, the MIP solid phase extraction is an alternative method for
\end{abstract}

extraction atenolol from the sample.

Key words: Atenolol, Molecular Imprinted Polymer, Solid Phase Extraction. Correspondence

Dr. Aliya Nur Hasanah, Department of Pharmaceutical Analysis and Medicinal Chemistry, Faculty of Pharmacy, Universitas Padjadjaran, Jatinangor 45363, INDONESIA.

Phone: +62 8122346382

Email: aliya.n.hasanah@unpad.ac.id

DOI: 10.5530/jyp.2019.11.3

\section{INTRODUCTION}

Doping refers to prohibited drug, substance or material that used by athlete to improve their performance. ${ }^{1}$ Various types of doping are used for reduce anxiety, increase muscle mass, reduce weight or to cover another drug during health check. Doping can cause harmful effect for human include myocardial infarction, hyperlipidemia, hypertension, thrombosis, heart failure and sudden death. ${ }^{2}$ Atenolol is one of betablocker group that usually used as doping by athlete to reduce anxiety, tremor and low heart rate. ${ }^{3}$ Doping analysis can be determined through metabolite or specimens examination. It requires sensitive instruments with pure samples and completely separated from the matrices. Numerous analytical method are used to determine atenolol such as High Performance Liquid Chromatography (HPLC). ${ }^{4}$ Gas ChromatographyMass Spectrometry (GC-MS) ${ }^{5}$ and diffuse reflectance spectroscopy. ${ }^{6}$ Recently, solid phase extraction (SPE) based on molecular imprinting polymer (MIP) has been developed as a separation technique is expected to be low cost, practical and applicable and has a high recovery percentage. Sorbents with molecular imprinting techniques have a recognizable binding sites that can bind with specific drug targets, thereby being able to separate drugs with complex matrices. Synthesis of molecular imprinted polymer consist of monomer, crosslinker, inisiator and porogen. Monomer must be able to interact with the template form a specific complex donor-receptor in polymerization. Methacrylic acid is an universal monomer that usually used in MIP. This monomer increase imprinting effect through dimerization reaction. ${ }^{7}$ Synthesis of MIP-SPE atenolol based on non-covalent bonding using methacrylic acid result the good sorbent with acetonitril or mix acetonitril as a porogen. ${ }^{8-10}$ Porogen that usually used in non-covalent bonding MIP is a solvent that has low dielectric constanta, tend to non-polar solvent, because polar solvent can interfere the hydrogen form. In this research, MIP-SPE atenolol was synthesized using methacrylic acid as functional monomer and butanol as a porogen by bulk and precipitation polymerization method.

\section{MATERIALS AND METHODS}

\section{Materials}

All of material used is analytical grade. Atenolol, metoprolol tartrate hydrochloride and propanolol hydrochloride were obtained from Tokyo Chemical Industry. Methacrylic acid and ethylene glycol dimethacrylate (EGDMA) were purchased from Sigma Aldrich. Acetone, alcohol 95\% and acetic acid 96\% were purchased from Brataco. Acetonitrile and methanol were obtained from Fischer Scientific. Butanol, benzoyl peroxide and potassium bromide were purchased from Merck. The absorbance measurement was recorded by UV-visible spectrophotometer (Analytical Jena Specord 200 using a $1.0 \mathrm{~cm}$ quartz cell). Identification of functional group was analyzed by Fourier Transform Infrared (FTIR) IR (Prestige-21 Shimadzu).

\section{Methods}

Determination of the Association Constant of MonomerTemplate Complex using UV Titration Method

Determination of the association constant can describes the interaction of monomer and template. Stock solution of atenolol in butanol was prepared in $2 \times 10^{-5} \mathrm{M}$ and methacrylic acid was $5 \times 10^{-3} \mathrm{M}$. Atenolol solution was measured by UV-visible spectrophotometer then methacrylic acid was added gradually until the absorbance tend to stable. The association constant was calculated by Benesi-Hildebrand equation. ${ }^{11}$

$$
\frac{1}{\Delta \mathrm{Y}}=\frac{1}{\mathrm{Y} \Delta_{\mathrm{HG}}} \mathrm{Ka}[\mathrm{G}]+\frac{1}{\mathrm{Y} \Delta_{\mathrm{HG}}}
$$


$\Delta \mathrm{Y}=$ Absorbance $;=$ Absorbance of $\mathrm{HG}$ complex - Absorbance of $\mathrm{H}$; $\mathrm{Ka}=$ Association constant; $[\mathrm{G}]=$ Consentration of guest (monomer).

\section{Synthesis of Molecular Imprinted Polymer by Precipitation Polymerization Method}

Methacrylic acid ( $4 \mathrm{mmol}$ ) as a monomer was added into atenolol solution in butanol $(1 \mathrm{mmol})$ as a template in $350 \mathrm{ml}$ solvent. The mixture was sonicated for $5 \mathrm{mins}$ in a closed vial. Then, $20 \mathrm{mmol}$ EGDMA as crosslinker was added and continued to sonicate for $20 \mathrm{mins}$. $1 \mathrm{mmol}$ benzoyl peroxide was added into solution as initiator, sonicated for $5 \mathrm{mins}$, then oven at $70^{\circ} \mathrm{C}$ for $2 \mathrm{hrs}$. The solution moves to water bath shaker at $70^{\circ} \mathrm{C}$ for $18 \mathrm{hrs}$. Subsequently, the solution was centrifuged and the precipitation was washed by methanol and water. The polymer was dried in oven at $60^{\circ} \mathrm{C}$ for $18 \mathrm{hrs}$. To verify the MIP results, the Non Imprinted Polymer (NIP) was also synthesized using this steps but without template.

\section{Synthesis of Molecular Imprinted Polymer by Bulk Polymerization Method}

Atenolol was dissolved in butanol $(1 \mathrm{mmol})$ in closed vial then $4 \mathrm{mmol}$ methacrylic acid was added and sonicated for 5 mins. EGDMA ( $20 \mathrm{mmol})$ as cross linker was added and continued to sonicate for 20 mind. Then, benzoyl peroxide $(1 \mathrm{mmol})$ as an initiator was added to the solution. The solution was moved to oven at $70^{\circ} \mathrm{C}$ for $2 \mathrm{hrs}$ and then to the water bath shaker at $70^{\circ} \mathrm{C}$ for $18 \mathrm{hrs}$. The polymer was mashed and filtered using a mesh size of 60 . Afterward, the polymer was rinsed with methanol and water then dried in oven at $70^{\circ} \mathrm{C}$ for $18 \mathrm{hrs}$. The Non Imprinted Polymer (NIP) was also synthesized using this steps but without template.

\section{Adsorption Capability Evaluation}

Evaluation of adsorption capability was carried out in methanol, acetonitrile, acetonitrile: methanol (1:1) and acetonitrile: methanol (1: 9). Sorbent of MIP (20 mg) was dissolved in atenolol solution of 5 ppm (in different solvent) and allowed to stand for $24 \mathrm{hrs}$. Filtrate from the mixture was measured by UV-Vis Spectrometry. The adsorption capability was calculated by the difference between the initial atenolol concentration and the free atenolol concentration in the filtrate. The NIP sorbent was also evaluated by the same procedure.

\section{Adsorption Capacity Evaluation}

Evaluation of adsorption capacity was carried out by varying the concentration of atenolol solution of 1, 2.5, 5, 7.5 and $10 \mathrm{ppm}$. A $5 \mathrm{ml}$ atenolol solution from each concentration was added into $20 \mathrm{mg}$ of MIP sorbent. The mixture was shake and allowed to stand for $24 \mathrm{hrs}$. The filtrate was measured by UV-Vis spectrometry. NIP sorbent was also evaluated by the same procedure. The adsorption capacity was calculated by using Freundlich isotherm adsorption curve. ${ }^{12-13}$

\section{MIP Selectivity Evaluation}

Evaluation of MIP selectivity was determined by calculating the coefficient of distribution of atenolol, metoprolol and propranolol solution at $5 \mathrm{ppm}$. A $5 \mathrm{ml}$ of each solution was added into $20 \mathrm{mg}$ of MIP sorbent. The mixture was shake and allowed to stand for $24 \mathrm{hrs}$. The filtrate was measured by UV-Vis spectrometry. NIP sorbent was also evaluated by the same procedure. The distribution coefficient was calculated by the following equation: ${ }^{14}$

$$
\mathrm{K}_{\mathrm{D}}=\frac{\mathrm{C}_{\mathrm{p}}}{\mathrm{C}_{\mathrm{s}}}
$$

$\mathrm{K}_{\mathrm{D}}$ is distribution coefficient, $\mathrm{Cp}$ is concentration of substrate in polymer ( $\mathrm{mol} / \mathrm{g}$ ) and Cs is concentration of substrate in solution $(\mathrm{mol} / \mathrm{g})$. The ratio of $K_{D}$ MIP and $K_{D}$ NIP was calculated as imprinting factor value. ${ }^{12}$

\section{RESULT}

Determination of the Association Constant of MonomerTemplate Complex using UV Titration Method

Interaction of monomer-template can be analyzed by determination of the association constant. Association constant was calculated based on slope and intercept on Bennesi-Hildebrand equation. Based on Figure 1, $\mathrm{Ka}$ of atenolol and methacrylic acid was $9.24 \times 10^{2} \mathrm{M}^{-1}$.

\section{Comparison of Physical Characterization of MIP by Precipitation and Bulk Polymerization Method}

Physical characterization of MIP was analyzed by using FTIR and SEM. FTIR to describe the functional group on the compound and SEM (Scanning Electron Microscope) to describe the morphology of the polymer. Table 1 and Table 2 show the FTIR analysis of MIP and NIP sorbent. The SEM analysis show in Figure 2 and Figure 3.

\section{Adsorption Capability Evaluation}

The results of adsorption capability of the MIP sorbent are shown in Figure 4 for the bulk polymerization and Figure 5 for precipitation polymerization.

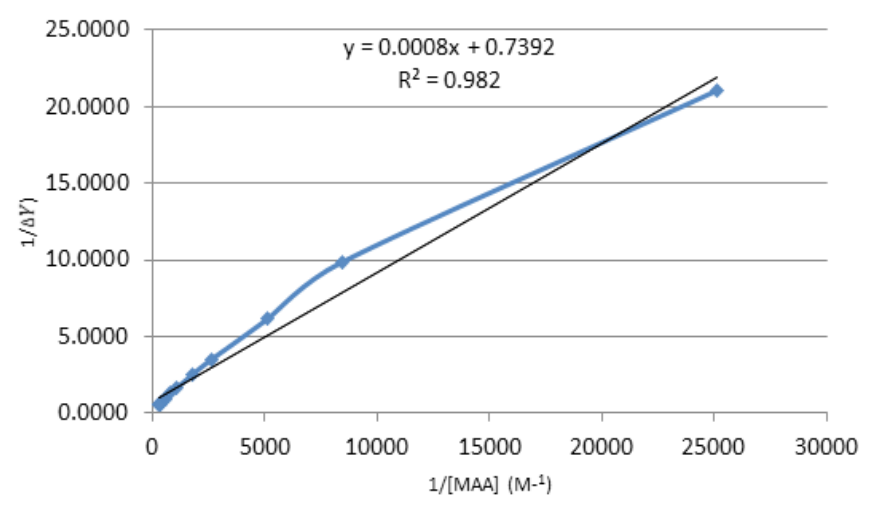

Figure 1: Graph of association constant of atenolol and methacrylic acid.

Table 1: FTIR analysis of MIP and NIP sorbent by bulk polymerization.

\begin{tabular}{|c|c|c|c|}
\hline \multicolumn{3}{|c|}{ Wave number $\left(\mathrm{cm}^{-1}\right)$} & \multirow[b]{2}{*}{$\begin{array}{l}\text { Functional } \\
\text { Group }\end{array}$} \\
\hline $\begin{array}{l}\text { Sorbent of } \\
\text { MIP before } \\
\text { extraction }\end{array}$ & $\begin{array}{l}\text { Sorbent of MIP } \\
\text { after extraction }\end{array}$ & Sorbent of NIP & \\
\hline 3580.91 & 3563.55 & 3594.41 & -OH stretching \\
\hline 3461.32 & - & - & N-H stretching \\
\hline 2347.71 & 2974.29 & 2974.29 & C-H stretching \\
\hline 1735.00 & 1734.04 & 1733.07 & $\mathrm{C}=\mathrm{O}$ stretching \\
\hline 1635.00 & 1633.74 & 1634.70 & $\mathrm{C}=\mathrm{C}$ stretching \\
\hline 1407.85 & 1466.89 & 1467.86 & $\mathrm{CH}_{2}$ bending \\
\hline 1100.20 & 1160.20 & 1162.13 & $\mathrm{C}-\mathrm{O}$ stretching \\
\hline
\end{tabular}


Table 2: FTIR analysis of MIP and NIP sorbent by precipitation

polymerization.

\begin{tabular}{cccc}
\multicolumn{3}{c}{ Wave number $\left(\mathrm{cm}^{-1}\right)$} & \\
\cline { 1 - 3 } $\begin{array}{c}\text { Sorbent of } \\
\text { MIP before } \\
\text { extraction }\end{array}$ & $\begin{array}{c}\text { Sorbent of MIP } \\
\text { after extraction }\end{array}$ & Sorbent of NIP & Functional Group \\
\hline 3590.55 & 3582.84 & 3571.26 & $-\mathrm{OH}$ stretching \\
3464.21 & - & - & N-H stretching \\
2980.78 & 2970.43 & 2971.39 & C-H stretching \\
1731.14 & 1729.21 & 1731.14 & C=O stretching \\
1635.66 & 1633.74 & 1635.66 & C=C stretching \\
1463.03 & 1464.00 & 1464.00 & CH bending \\
1157.31 & 1157.31 & 1156.34 & C-O stretching \\
\hline
\end{tabular}
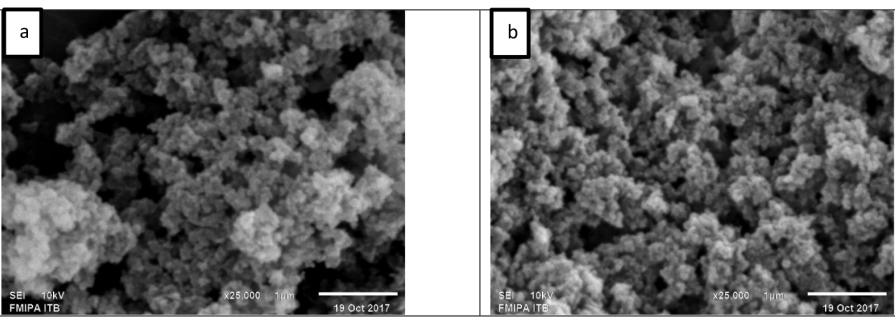

Figure 2: SEM analysis of MIP (a) and NIP (b) by bulk polymerization.
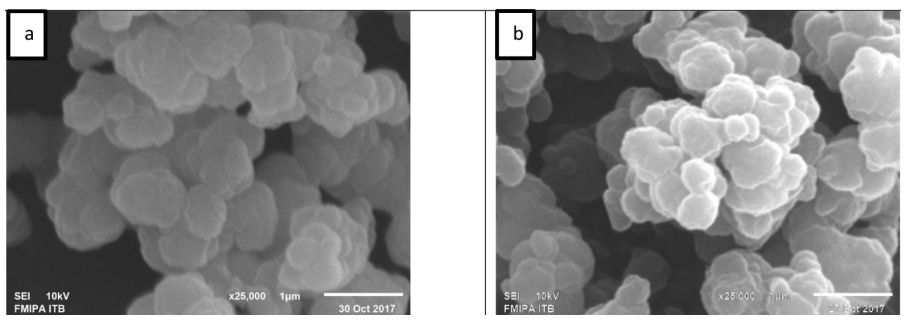

Figure 3: SEM analysis of MIP (a) and NIP (b) by precipitation polymerization.

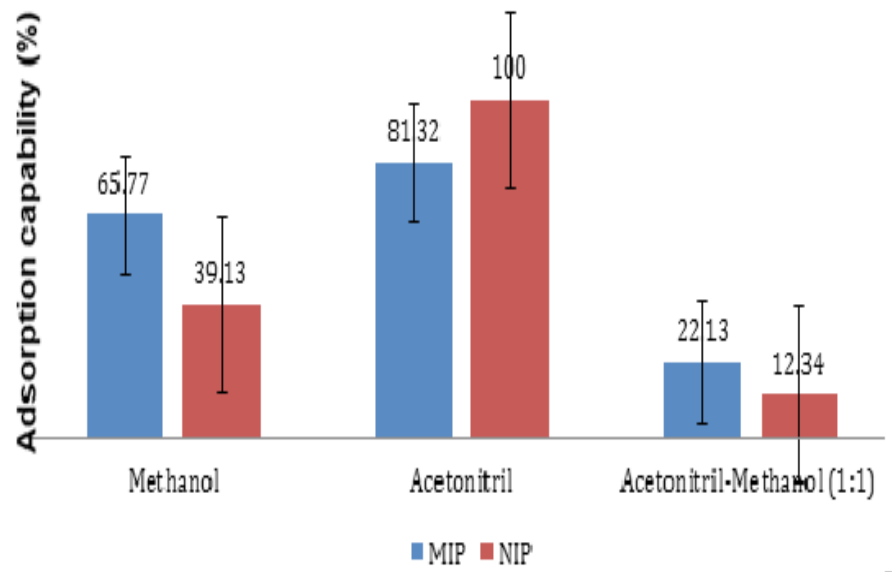

Figure 4a: Graph of adsorption capability of MIP and NIP sorbent by bulk polymerization $(n=3)$.

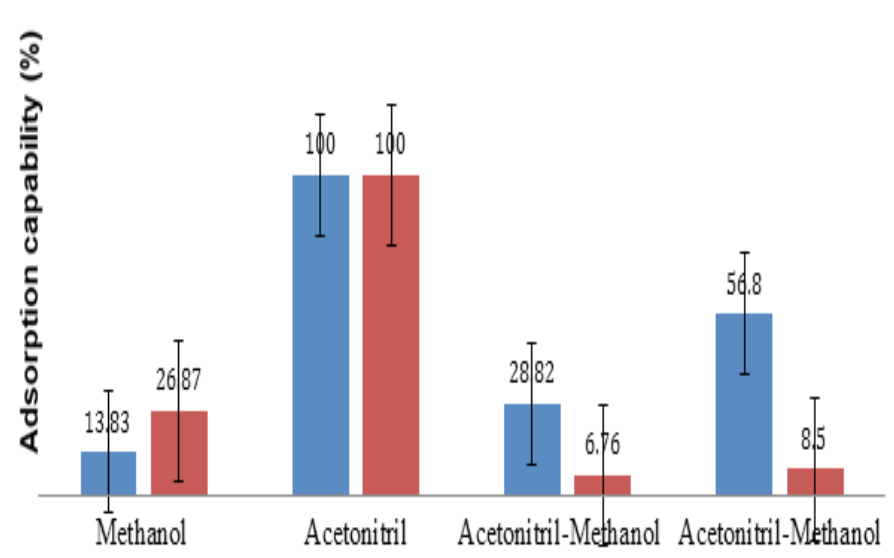

$(1: 1)$

(1:9)

Figure 4b: Graph of adsorption capability of MIP and NIP sorbent by precipitation polymerization $(n=3$, mean $\pm S D)$

Table 3: The adsorption capacity of MIP and NIP sorbent of bulk and precipitation polymerization.

\begin{tabular}{ccccc}
\hline \multirow{2}{*}{ Value } & \multicolumn{2}{c}{ Bulk polymerization } & \multicolumn{2}{c}{ Precipitation polymerization } \\
\cline { 2 - 5 } & MIP & NIP & MIP & NIP \\
\hline $\mathrm{m}$ & 0.893 & 0.757 & 2.567 & 1.197 \\
$\mathrm{a}(\mathrm{mg} / \mathrm{g})$ & 7.804 & 4.819 & 2.950 & 5.740 \\
$\mathrm{r}$ & 0.81 & 0.99 & 0.83 & 0.71 \\
\hline
\end{tabular}

Table 4: Selectivity of MIP and NIP Sorbent by bulk polymerization ( $n=3)$.

\begin{tabular}{ccccc}
\hline \multicolumn{2}{c}{ Analyte } & Atenolol & Propranolol & Metoprolol \\
\hline \multirow{2}{*}{ KD } & MIP & $486.97 \pm 2.0$ & $101.42 \pm 0.5$ & $195.04 \pm 0.5$ \\
& NIP & $169.80 \pm 2.1$ & $83.19 \pm 0.6$ & $530.73 \pm 0.7$ \\
\multicolumn{2}{l}{ Imprinting Factor } & $2.87 \pm 0.2$ & $1.22 \pm 0.5$ & $0.37 \pm 0.4$ \\
\hline
\end{tabular}

\section{Adsorption Capacity Evaluation}

The adsorption capacity was calculated by using Freundlich isotherm adsorption curve. The result show in Table 3.

\section{MIP SelectivityEvaluation}

Evaluation of MIP selectivity was determined by calculating the coefficient of distribution and imprinting factor. Table 4 show the selectivity of MIP and NIP Sorbent by bulk polymerization and Table 5 show the selectivity of MIP and NIP Sorbent by precipitation polymerization.

\section{DISCUSSION}

Interaction of methacrylic acid as a monomer and atenolol as a template can be analyzed by determination of the association constant. Generally, the better and stronger interactions that occur, the better of the imprinting effect and the more stable of the complex during polymerization. ${ }^{15}$ Therefore, the interaction of monomer-template must be tested by noncovalent imprinting stoichiometry study.$^{16}$ In this study, the interaction was determined based on association constant value (Ka). If the $\mathrm{Ka}$ is around $10^{3} \mathrm{M}^{-1}$, the complex is stable and the binding site has a good performance with recovery value more than $90 \% .{ }^{17}$ Based on Figure 1, 
Table 5: Selectivity of MIP and NIP Sorbent by precipitation polymerization $(n=3)$.

\begin{tabular}{ccccc}
\hline \multicolumn{2}{c}{ Analyte } & Atenolol & Propranolol & Metoprolol \\
\hline \multirow{2}{*}{ KD } & MIP & $325.43 \pm 3.1$ & $44.51 \pm 0.4$ & $207.62 \pm 0.2$ \\
& NIP & $78.22 \pm 2.1$ & $68.79 \pm 0.5$ & $191.30 \pm 0.3$ \\
\multicolumn{2}{l}{ Imprinting Factor } & $4.16 \pm 2.1$ & $0.65 \pm 0.3$ & $1.09 \pm 0.2$ \\
\hline
\end{tabular}

Ka of atenolol and methacrylic acid was $9.24 \times 10^{2} \mathrm{M}^{-1}$. This value is close to the expected value, so it can be predicted that the interaction of monomer and template are strong.

FTIR analysis can confirm the success of co-polymerization step. ${ }^{18}$ The -OH stretching band in Table 1 and Table 2 related to the carboxylic group (-COOH) in the monomer of methacrylic acid. The $-\mathrm{CH}$ and $\mathrm{CH}_{2}$ stretching related to the methylene group in methacrylic acid and EGDMA. The strong intensity of wavenumber around $1700 \mathrm{~cm}^{-1}$ show the functional group of $\mathrm{C}=\mathrm{O}$ from EGDMA, methacrilic acid and benzoyl peroxide. The absence of twin peaks in the area of the wave number $900-1000 \mathrm{~cm}^{-1}$ indicates the absence of a vinyl group which means the polymerization process is complete.

Scanning Electrone Microscope was used to describe the geometry, particle size and surface of the polymer. Based on Figure 2 and Figure 3, the surface of NIP is more smooth and homogeneous compare to MIP which has a coarser and large cavity as a results from template extraction. It indicates that the specific cavity is formed. Polymer from precipitation polymerization method have a surface with relatively larger particles compare to the bulk polymerization.

The sorbent that has been synthesized will absorb the analyte. In this process needed to find the optimum condition to be able to absorb analytes to the fullest. One of the important thing in the test of sorbent-analyte binding is polymerization technique and the use of solvents during binding testing. ${ }^{19}$ In this research, the solvent variations were tested for the adsorption ability of MIP and NIP. Figure 4 show that the MIP sorbent by bulk polymerization has the optimum adsorption in methanol and acetonitrile at 65.77 and $81.32 \%$, respectively. In acetonitrile, NIP has the higher adsorption compare to the MIP. Atenolol more easily dissolve in methanol than acetonitrile. In this condition, methanol can bring the atenolol to the binding site that spread in MIP. In the other hand, methanol also can bring back atenolol which has less interaction at the binding site. Acetonitrile has a lower interaction with atenolol. When it reacts with acetonitrile, atenolol will dissolve first then bring to the binding site. When interaction of analyte-MIP is stronger than analyte-solvent, analyte will retain in MIP. ${ }^{20}$ Therefore, adsorption capability of acetonitrile is haigher than methanol. However, in acetonitril the capability of MIP is lower than NIP, so that methanol was choosen as a solvent because has a higher adsorption capability of MIP. In the precipitation polymerization, acetonitrile, acetonitril:methanol (1:1) and acetonitril:methanol (1:9) has a good MIP adsorption. Although the adsorption in acetonitril was $100 \%$ for MIP and NIP, acetonitril:methanol (1:9) was choosen as a solvent because in this condition MIP has a better activity than NIP.

The adsorption capacity was determined by using Freundlich isotherm adsorption curve. This system describes the adsorption in heterogen surface. ${ }^{21}$ Freundlich isotherm describes the correlation between the equilibrium of the number of analytes bound to the adsorbent (B) and the number of analytes that remain free $(\mathrm{F})$ as the equation: ${ }^{22}$

$$
\log \mathrm{B}=\log \mathrm{a}+\mathrm{m} \log \mathrm{F}
$$

$\mathrm{a}$ is the adsorbent affinity and $\mathrm{m}$ is a adsorbent homogeneity. If the value of the $\mathrm{m}$ is 0 , it indicates that the system is non-homogenous, meanwhile if the value of $\mathrm{m}$ is 1 the system is homogenous. ${ }^{23}$
In the bulk polymerization, MIP has the $\mathrm{m}$ value close to 1 means that MIP is more homogenous than NIP. The value of a describe the adsorbent capacity in absorb the analyte. In bulk polymerization, MIP has able to absorb up to $7.804 \mathrm{mg} / \mathrm{g}$ compare to the NIP. It is indicates the binding site of the sorbent is complement with the shape and size of the template. However, this value is still relatively small because the amount of analyte that can be absorbed is small, so so it takes a large amount of sorbent to absorb more analytes. In the precipitation polymerization, MIP less homogenous than the NIP because NIP has the $m$ value close to 1 . Besides that, MIP has the less adsorption capacity compare to the NIP. It can be conclude that adsorption capacity of MIP from bulk polymerization is better than from precipitation polymerization.

The selectivity of MIP was carried out by using metoprolol and propranolol, as a same beta blocker group with atenolol. The selectivity was determined by calculating distribution coefficient distribution that describes the number of analytes absorbed to the concentration of analytes in solution. ${ }^{14}$ In the bulk and precipitation polymerization, $\mathrm{KD}$ of atenolol is higher than others. It indicates that MIP sorbent is selective for atenolol. MIP was synthesized using atenolol as a template so the cavity of the MIP was formed the cavity for the atenolol. Imprinting factor is also calculated to see the ratio between MIP and NIP. It is describes the performance of MIP. Both of method has the higher imprinting factor of atenolol compare to the others and precipitation polymerization has the higher imprinting factor of atenolol than bulk polymerization. It is indicates that selectivity of MIP form precipitation method is better than bulk method, however both of method has the good performance compare to NIP.

\section{CONCLUSION}

The sorbent of MIP can be synthesized by using methacrylic acid as a monomer, butanol as a porogen and EGDMA as a crosslinker with ratio 1:4:20. The sorbent of MIP can be synthesized by using both of method, bulk and precipitation polymerization method. The result show that polymer from precipitation polymerization have a surface with relatively larger particles compare to the bulk polymerization. The sorbent from bulk polymerization has the higher adsorption capacity $(7.804 \mathrm{mg} / \mathrm{g})$ compare to the polymerization method $(2.95 \mathrm{mg} / \mathrm{g})$. Both of method are selective for atenolol but MIP form precipitation method is more selective than bulk method.

\section{ACKNOWLEDGEMENT}

Financial support from the Ministry of Research and Higher National Education of Indonesia through Penelitian Terapan Unggulan Perguruan Tinggi (PTUPT) research scheme in 2017-2018 are greatly acknowledged.

\section{CONFLICT OF INTEREST}

The authors declare no conflict of interest.

\section{ABBREVIATIONS}

SPE: Solid Phase Extraction; MIP: Molecular Imprinted Polymer; NIP: Non Imprinted Polymer; EGDMA: Ethylene Glycol Dimethacrylate; FTIR: Fourier Transform Infrared; SEM: Scanning Electron Microscope.

\section{REFERENCES}

\footnotetext{
1. UNESCO. What is Doping [Internet]. 2017 [cited 2018 Oct 1]. Available from: http://www.unesco.org/new/en/social-and-human-sciences/themes/antidoping/youth-space/what-is-doping/
} 
2. Deligiannis A, Bjornstad $H$, Carre F, Heidbuchel H, Kouidi E, PanhuyzenGoedkoop NM, et al. ESC Study Group of Sports Cardiology Position Paper on adverse cardiovascular effects of doping in athletes. Eur J Prev Cardiol. 2006;13(5):687-94

3. Reardon C, Creado S. Drug abuse in athletes. Subst Abuse Rehabil [Internet]. 2014;95. Available from: http://www.dovepress.com/drug-abuse-in-athletespeer-reviewed-article-SAR

4. Yilmaz B, Arslan S, Asci A. HPLC method for determination of atenolol in human plasma and application to a pharmacokinetic study in Turkey. J Chromatogr Sci. 2012;50(10):914-9.

5. Yilmaz B, Arslan S. Determination of atenolol in human urine by gas chromatography-mass spectrometry method. J Chromatogr Sci. 2011;49(5):365-9.

6. Gotardo MA, Sequinel R, Pezza L, Pezza HR. Determination of atenolol in pharmaceutical formulations by diffuse reflectance spectroscopy. Eclet Quim. 2008;33(4):7-12.

7. Golker K, Karlsson BCG, Olsson GD, Rosengren AM, Nicholls IA. Influence of Composition and Morphology on Template Recognition in Molecularly Imprinted Polymers. Macromolecules. 2013:46(4):1408-14. Available from: http://pubs. acs.org/doi/abs/10.1021/ma3024238

8. Bompart M, Gheber LA, De WildeY, Haupt K. Direct detection of analyte binding to single molecularly imprinted polymer particles by confocal Raman spectroscopy. Biosens Bioelectron. 2009;25(3):568-71.

9. Zaidi SA, Lee SM, Cheong WJ. Open tubular capillary columns with basic templates made by the generalized preparation protocol in capillary electrochromatography chiral separation and template structural effects on chiral separation capability. J Chromatogr A. 2011;1218(9):1291-9.

10. Andreetta HA, Bruzzone L. Fluorescence detection of atenolol using a molecular imprinted polymer. Anal Lett. 2008;41(1):36-45.

11. Thordarson P. Determining association constants from titration experiments in supramolecular chemistry. Chemical Society Reviews. 2011;40(3):1305-23.

12. Hasanah AN, Sari TN, Wijaya N, Kartasasmita RE, Ibrahim S. Study of the binding ability of molecular imprinted solid phase extraction for glibenclamide by opti- mizing template: Monomer: Crosslinker ratio. Int J Chem Sci. 2014;12(3):863-70.

13. Hasanah AN, Kartasasmita RE, Ibrahim S. Synthesis and Application of Glibenclamide Imprinted Polymer for Solid Phase Extraction in Serum Sample Using Itaconic Acid as Functional Monomer. J Appl Sci. 2015;15(11):1288-96.

14. Liu P, Liu L, Zhang L, Jiang N, Liu Z, Wang Y. Synthesis and characterization of molecularly imprinted polymers for recognition of ciprofloxacin. Front Chem China. 2008;3(4):378-83.

15. Hashim SNNS, Boysen RI, Schwarz LJ, Danylec B, Hearn MTW. A comparison of covalent and non-covalent imprinting strategies for the synthesis of stigmasterol imprinted polymers. J Chromatogr A. 2014;1359:35-43.

16. Wulff $G$, Knorr K. Stoichiometric noncovalent interaction in molecular imprinting. Bioseparation. 2001;10(6):257-76.

17. Lorenzo CA, Concheico A. Handbook of Molecularly Imprinted Polymers. Shawburry, UK: Smithers Rapra. 2013;26-31.

18. Sikiti $P$, Msagati TAM, Mamba BB, Mishra AK. Synthesis and characterization of molecularly imprinted polymers for the remediation of PCBs and dioxins in aqueous environments. J Environ Heal Sci Eng. 2014;12(1);82.

19. Pérez-Moral N, Mayes AG. Comparative study of imprinted polymer particles prepared by different polymerisation methods. Anal Chim Acta. 2004;504(1):15-21.

20. Cai W, Gupta RB. Molecularly-imprinted polymers selective for tetracycline binding. Sep Purif Technol. 2004;35(3):215-21.

21. Lahsini R, Louhaichi MR, Adhoum N, Monser L. Preparation and application of a molecularly imprinted polymer for determination of glibenclamide residues. Acta Pharm. 2013;63(2):265-75.

22. Ansell RJ. Characterization of the Binding Properties on Molecularly Imprinted Polymers. Adv Biochem Eng Biotechnol. 2015;150:51-93.

23. Rushton GT, Karns CL, Shimizu KD. A critical examination of the use of the Freundlich isotherm in characterizing molecularly imprinted polymers (MIPS). Anal Chim Acta. 2005;528(1):107-13.

Article History: Submission Date : 15-11-2018; Revised Date : 05-12-2018; Acceptance Date : 12-12-2018.

Cite this article: Pratiwi R, Megantara S, Rahayu D, Pitaloka I, Hasanah AN. Comparison of Bulk and Precipitation Polymerization Method of Synthesis Molecular Imprinted Solid Phase Extraction for Atenolol using Methacrylic Acid. J Young Pharm. 2019;11(1):12-6. 